\title{
Optical, Electrical And Structure Investigation of Perylene Doped Polycarbonate
}

\author{
N. Hendawy, T. Y. Elrasasi *, M. El-Mansy \\ Department of Physics, Faculty of science, Benha University, Egypt
}

Perylene/Polycarbonate composite (PPC) layers were prepared by solution-casting method. The optical absorption of PPC was studied in the range (400-1100 nm) for different concentrations of Perylene from $10 \mathrm{ppm}$ up to $200 \mathrm{ppm}$. It showed absorption characteristic peak at $574 \mathrm{~nm}$ which increased with dye concentration. The detection of fluorescence of polymer composite illustrated a fluorescence peak at $612 \mathrm{~nm}$ with maximum intensity at 200 ppm. The polymer composites were characterized by using $D S C, T G A$ up to $600^{\circ} \mathrm{C}$, and FT-IR in the range (400-4000 $\left.\mathrm{cm}^{-1}\right)$ which did not illustrate any structure variation with the addition of Perylene dye up to 200 ppm. Bulk resistances, conductivity and dielectric parameters were studied.

\section{Introduction}

Recently, polymer composites have attracted the attention of scientists due to their wide and attractive different properties e.g. easy manufacturing, weathering durability, light weight and good optical and mechanical properties [1]. Polymer composites can be used in numerous modern applications, such as organic solar cells, thermal and photo solar collectors, displaying, semiconductors and greenhouses applications. The greenhouse applications such as planting, vegetables and fruits drying and desalination need suitable polymeric film for covering the greenhouse to create a good environment conditions. The polymeric film should be transparent, has good mechanical properties, good UV resistance degradation, and thermal stability [2].

Many polymers are used in the greenhouse applications such as clear polyvinyl chloride (PVC), Polymethyl methacrylate (PMMA), Polycarbonate (PC), Polyethylene (PE), and Polypropylene (PP) [3]. PE and PP are used because of their low cost and good mechanical properties [4]. On the other hand, PMMA and $\mathrm{PC}$ are used because of their perfect optical properties [5].

PC is one of the most thermoplastic polymers used in the greenhouse applications because it is often colorless, high transmission to the visible light up to $90 \%$, high refractive index (1.588) and density lower than most types of glasses $\left(1.52 \mathrm{~g} / \mathrm{cm}^{3}\right)[6]$. 
Fluorescent polymer composites (FPCs) which used in greenhouse applications are consists of a suitable transparent polymer doped with an organic or inorganic fluorescent material. FPCs are used to convert the unused solar spectra into favorable spectra which can increase the performance in the greenhouse applications.

Perylene fluorescent organic red dye is used in FPCs because it has high fluorescence quantum yield, photo and thermal stability, with emission peak in the near infra-red region $[7,8]$.

The aim of this work synthesis of PC doped with perylene dye emitting photons in deep red and used in greenhouse applications. The optical absorption and fluorescence of all dye-polymer composites are analyzed in detail. In addition, the quantum efficiency spectra of the prepared films have been presented. Besides, different thermal analyses of the FPCs were studied to examine the thermal stability of such polymer composites.

\section{Experimental}

\subsection{Material processing}

PC was provided by Styron Europe, Germany, which have excellent transparency, high heat resistance [6]. Perylene fluorescent red dye was provided by Kremer pigment. In addition, dichloromethane $\left(\mathrm{CH}_{2} \mathrm{CL}_{2}\right)$ was used as a common solvent for PC and Perylene as well.

Perylene-polycarbonate composite films were prepared by solution-casting method. PC and Perylene were dissolved in dichloromethane and stirred for 30 min at room temperature. After that, perylene was added to PC solution at different concentrations from $10 \mathrm{ppm}$ up to $200 \mathrm{ppm}$ (concentrations was calculated by solid PC/solid dye). Then, the samples (Perylene-PC) were casted in Petri-glass dishes and lift at $70{ }^{\circ} \mathrm{C}$ for (35) min to get a completely dry.

\subsection{Sample characterization}

The absorption spectra of the prepared films were investigated in the wavelength range $(190-1100 \mathrm{~nm})$ by using T80 UV/VIS spectrophotometer, pg instrument. Fluorescent properties of the prepared films were investigated by rf5301 pc spectro-fluorophotometer, shim adzu, 150W Xenon lamp, wavelength range (220 $-900 \mathrm{~nm})$. FT-IR spectra were examined by using 6300 Fourier transform infrared spectrometer in the wave number range $\left(400-4000 \mathrm{~cm}^{-1}\right)$. Thermo-gravimetric (TGA) data were obtained by using Shimadzu thermal analyzer system at a heating rate of $20^{\circ} \mathrm{C} / \mathrm{min}$, under $\mathrm{N}_{2}(20 \mathrm{ml} / \mathrm{min})$ flow in the range from room temperature up to $600^{\circ} \mathrm{C}$. Thermo-analytical data were obtained by using PerkinElmer DSC-7 power compensation differential scanning 
calorimeter. Finally, dielectric and electrical measurements were carried out in the room temperature using pm 6304 programmable automatic (RLC Philips meter). The measurements were carried out over a frequency range $100 \mathrm{~Hz}$ to 20 $\mathrm{kHz}$.

\section{Results and Discussion}

\subsection{Optical Absorption}

The absorption spectra for all Perylene-PC composite films are shown in Fig.1, which illustrates two major absorption bands at 540 and $574 \mathrm{~nm}$ respectively. One can see that the maximum absorption wavelength $\left(\lambda_{m}\right)$ for all concentrations is $574 \mathrm{~nm}$ i.e. at the green-yellow optical band. Moreover, as shown in Fig.2, the area under the absorption curves and the absorption intensity increases by increasing the dye concentration; this can be attributed to the increase of absorbing dye molecules.

The absorbance $\boldsymbol{A}$ can be explained by Lambert-Beer's law, Eq. (1)

$$
A=C d \alpha(\lambda)
$$

where $C$ is the dye concentration, $d$ is the thickness and $\alpha$ is the absorption coefficient.

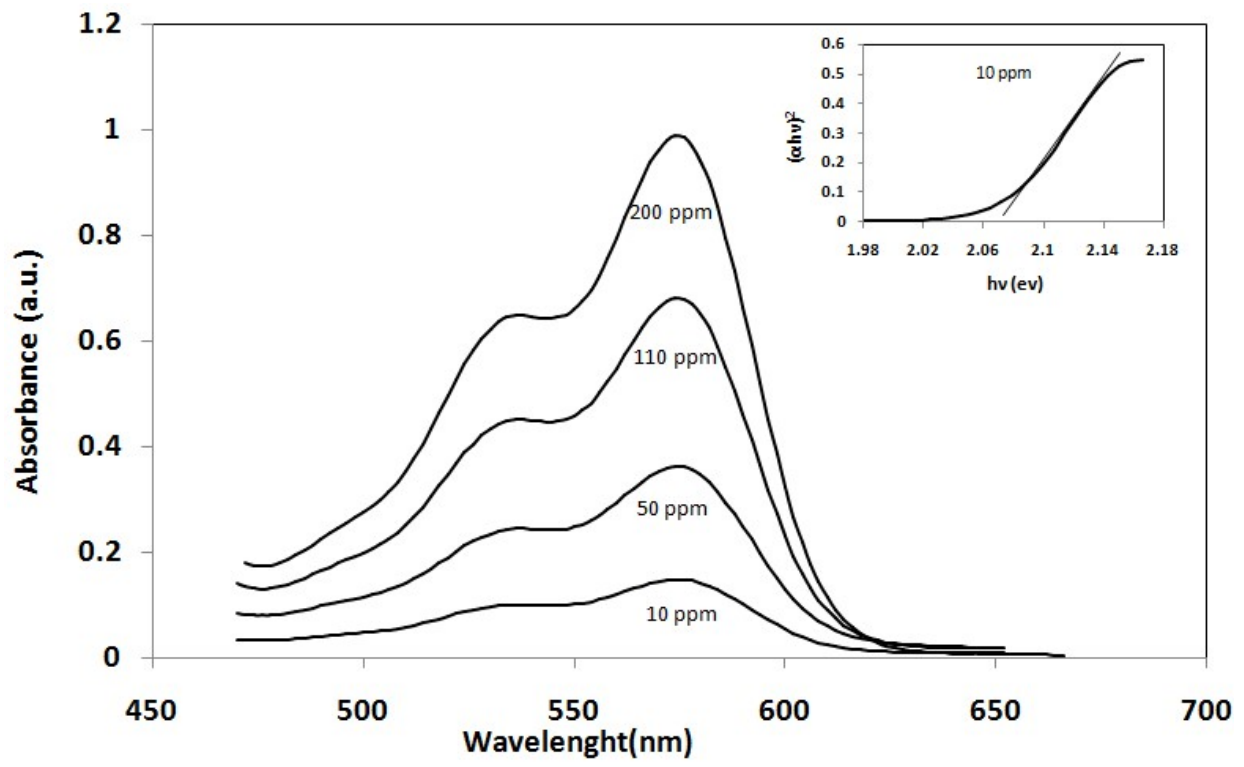

Fig. (1): The absorption spectra of perylene-PC composites at different concentrations, inset $h v$ vs. $\alpha h v^{2}$ at concentration $10 \mathrm{ppm}$. 


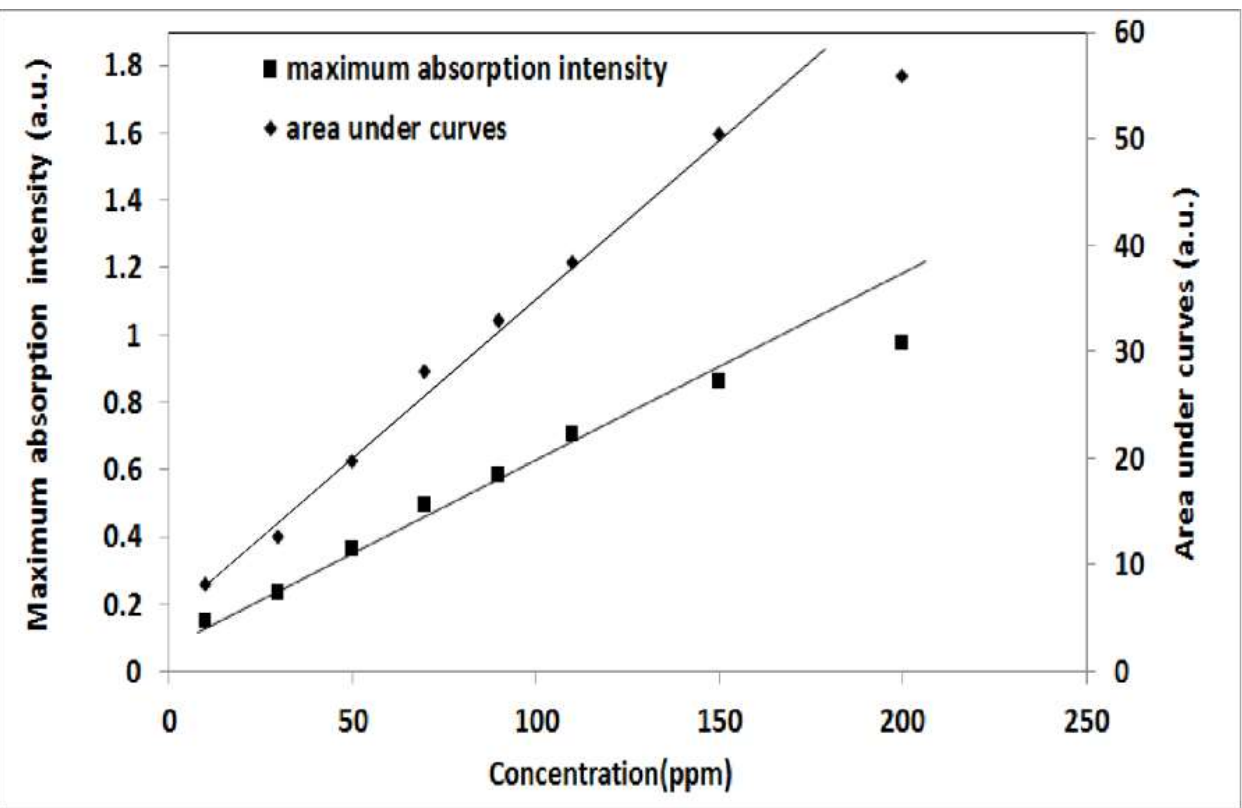

Fig. (2): Area under absorption curves and maximum absorption intensity of Perylene-PC composites at different concentrations.

\subsection{Optical Band Gaps ( $\left.\mathrm{E}_{\mathrm{g}}\right)$}

The electronic transitions are the essential parameter of the optical absorption. These transitions are controlled by certain selection rules, which can be expressed by Eq. (2).

$$
\alpha h v=A\left(h v-E_{g}\right)^{n}
$$

where $h v$ is the photon energy, $\alpha$ is the absorption coefficient, $A$ is a constant, and $n$ has certain values, with allowed values of $1 / 2$ and 2 and not allowed values of $3 / 2$ and 3 for direct and indirect transitions respectively $[9,10]$. To ascertain the transition mode, $n$ has been obtained using the first derivative of Eq. (2) and absorption data; it is in the range (0.925-1.083) which predicts the electronic allowed direct transition. To determine the direct optical energy gap, the $\alpha h v^{2}$ was plotted vs. $h v$ as shown in inset of Fig.1. The values of the direct inter band transition were estimated from the intercept of the energy axis as listed in Table 1 [11]. Table 1 shows that there is no change in the energy gap of Perylene-PC composites at different concentrations of perylene, which confirms that the electronic transition is belonging to perylene orbital transitions $\left(\mathrm{S}_{0} \rightarrow \mathrm{S}_{1}\right)$ [12]. 
Table (1): Optical parameters of perylene-PC composites at different concentrations.

\begin{tabular}{|c|c|c|c|c|c|c|}
\hline $\begin{array}{c}\text { Concentra } \\
\text { tion (ppm) }\end{array}$ & $\begin{array}{c}\text { Area under } \\
\text { absorption } \\
\text { curve(a.u.) }\end{array}$ & $\begin{array}{c}\text { Area under } \\
\text { fluorescence } \\
\text { curve (a.u.) }\end{array}$ & $\begin{array}{c}\text { Maximum } \\
\text { absorption } \\
\text { intensity (a.u.) }\end{array}$ & $\begin{array}{c}\text { Maximum } \\
\text { fluorescence } \\
\text { intensity (a.u.) }\end{array}$ & $\begin{array}{c}\mathrm{E}_{\mathrm{g}} \\
\text { (ev) }\end{array}$ & $\begin{array}{c}\text { Intersect } \\
\text { ion area } \\
\text { (a.u.) }\end{array}$ \\
\hline 10 & 8.023 & 10340 & 0.145 & 195.19 & 2.08 & 0.929 \\
\hline 30 & 12.535 & 11412 & 0.231 & 220.56 & 2.08 & 1.624 \\
\hline 50 & 19.591 & 12484 & 0.36 & 247.47 & 2.08 & 2.564 \\
\hline 70 & 27.991 & 16099 & 0.49 & 302.47 & 2.08 & 3.45 \\
\hline 90 & 32.839 & 17171 & 0.58 & 319.75 & 2.08 & 3.993 \\
\hline 200 & 55.724 & 20045 & 0.97 & 373.011 & 2.08 & 5.814 \\
\hline 110 & 38.242 & 18375 & 0.7 & 330.731 & 2.08 & 4.6 \\
\hline 150 & 50.31 & 19791 & 0.86 & 351.71 & 2.08 & 5.207 \\
\hline
\end{tabular}

\subsection{Optical Fluorescence}

The fluorescence spectra for all perylene-PC composites are shown in Fig. (3). It is clear that, the fluorescence spectra are a typical invert image of the optical absorption spectra. The maximum fluorescence intensity and the area under the fluorescence curves increases with increasing perylene concentration from 50 ppm up to $200 \mathrm{ppm}$ with two different regions, see Fig. (4). On other words, by increasing the perylene concentration, the absorption and emission sites in PC increase. On the other hand, from Fig. (3), the maximum fluorescence wavelength for all concentrations of Perylene-PC composites is $612 \mathrm{~nm}$ i.e. with a stoke shift $38 \mathrm{~nm}$.

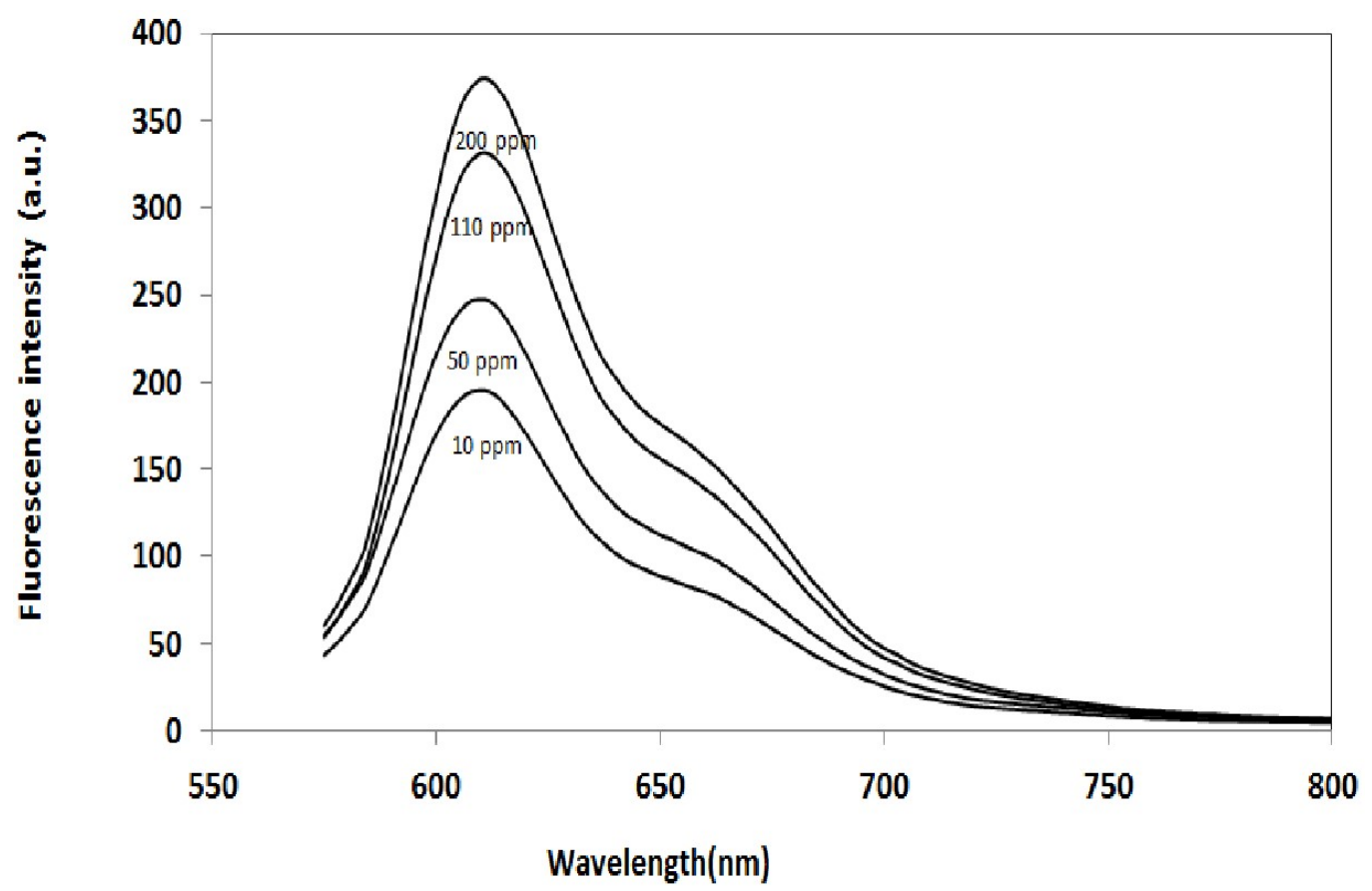

Fig.(3): The fluorescence spectra of perylene-PCcomposites at different Concentrations 


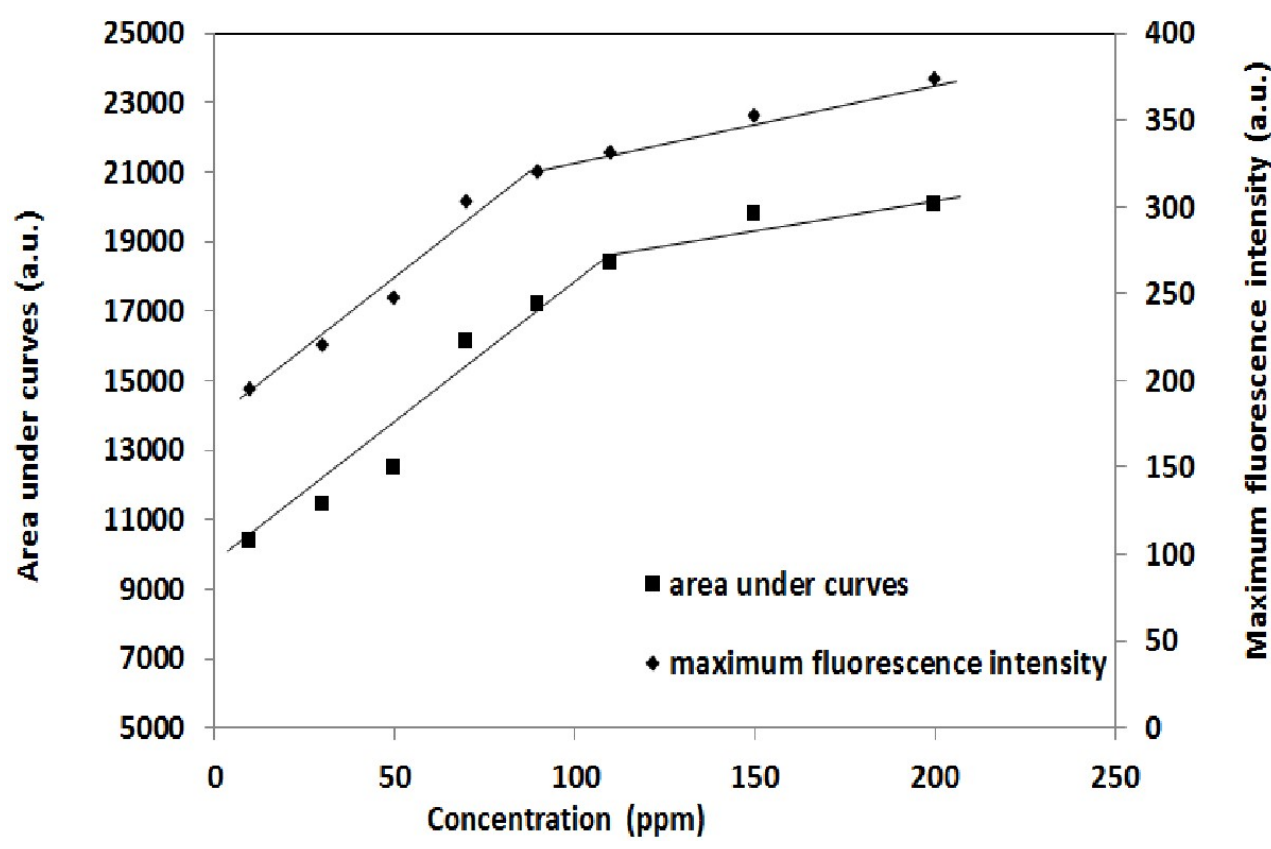

Fig. (4): Area under fluorescence curves and maximum fluorescence intensity of PerylenePC composites at different concentrations.

As shown in Fig. (4), the relation illustrates knee around (90-110 ppm) which can be attributed to the start self-absorption of perylene of emitted photons.

It is clear that the addition of perlyne dye to PC matrix up to a certain concentration, an aggregation of perlyne molecules occurred. At such concentration the emission of perlyne gets reabsorption to the nearest perlyne molecules of aggregate which resulted in a fluorescence quenching.

As a result, both the fluorescence intensity and the area under the curve illustrate two straight lines, the first at law concentration of perlyne with higher slope and the second with reduced slope due to fluorescence quenching at higher perlyne concentration. Table (2) illustrates the increase of the intersection area between absorption and fluorescence curve by increasing the concentration of the perlyne dye.

\subsection{Optical Quantum efficiency}

The optical quantum efficiency $(\boldsymbol{\phi})$ is defined as the ratio of emitted photons to the absorbed photons [13], which is proportional to the area under fluorescence $\mathrm{A}_{\text {flu }}$ curves to the area under absorption curves $\mathrm{A}_{\text {abs }}$ neglecting the scattered and reflected photons, see Eq. (3). 


$$
\begin{aligned}
& \phi=\frac{\text { no of emitted photons }}{\text { no of absorbed photons }} \\
& \frac{\text { no of emitted photons }}{\text { no of absorbed photons }} \overbrace{A_{a b s}}^{A \text { flu }}=B
\end{aligned}
$$

The ratio $A_{f l u} / A_{a b s}=B$ has been obtained by using the absorption and fluorescence curves at different concentrations of perylene in PC polymer matrix. Fig. (5), shows quantum yield $B$ vs. Perylene concentration, one can see that, $B$ decreases by increasing the concentration of Perylene; this can be attributed to the energy transfer among fluorescent molecules, obeying the exponential relation.

$$
B=B_{o} \operatorname{EXP}\left(-C / C_{o}\right)
$$

Where $C_{0}$ is the characteristic concentration of perylene in PC.

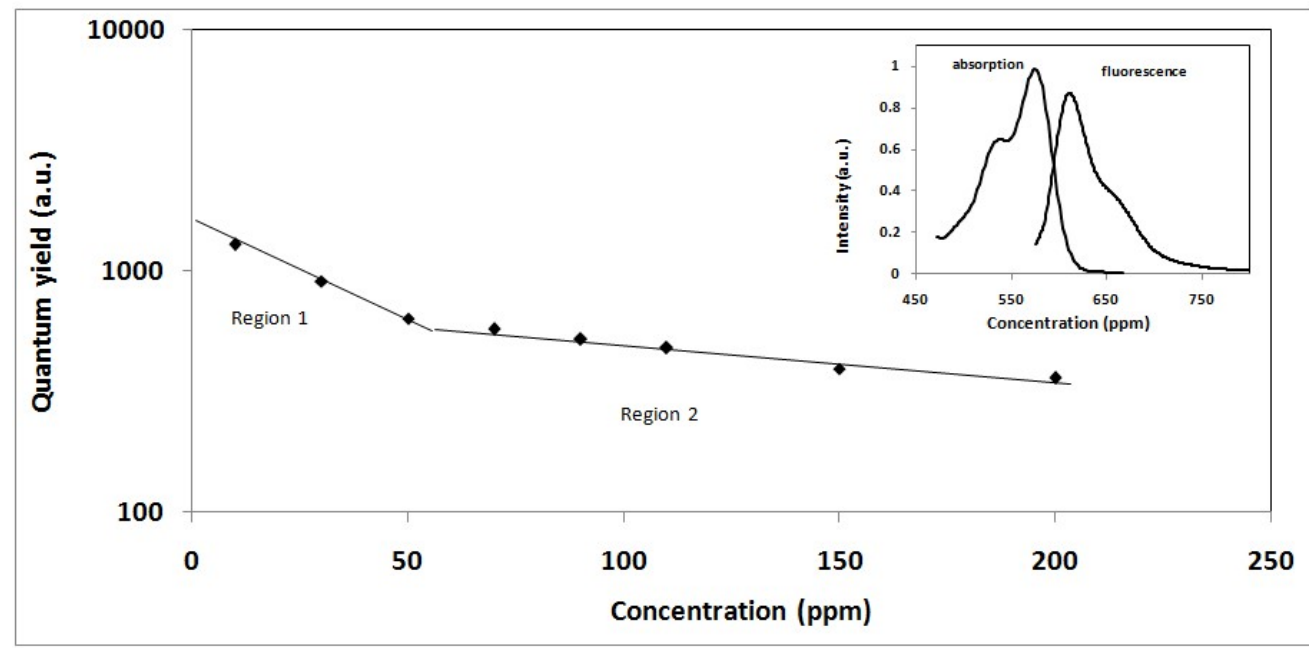

Fig. (5): Quantum yield of Perylene-PC composites at different concentrations, inset intersection area between absorption and fluorescence curves.

The values of $\mathrm{B}_{\mathrm{o}}$ and $\mathrm{C}_{\mathrm{o}}$ fitting parameters are obtained in the two regions 1 and 2 as shown in Fig. (5).

$$
B_{01}=1539 \quad C_{01}=55.5 \mathrm{ppm} \quad B_{02}=727.7 \quad C_{02}=250 \mathrm{ppm}
$$

By drawing the absorption and fluorescence curves for all concentrations together as shown in inset of Fig. (5), the intersection area between absorption and fluorescence curves increase by increasing the dye concentration, as listed in Table (1).

During the energy transfer between fluorescent molecules, a photon from an energetically excited fluorescent molecule 'donor' raises the energy state of an electron in another fluorescent molecule 'acceptor' to higher vibrational levels of the excited singlet state. So, the energy level of the donor molecule returns to the ground state, without emitting its own fluorescence. This mechanism depends on 
the dipole orientations of both fluorescent molecules and is limited by the distance between the two molecules. Ideal effective distances between the donor and acceptor molecules are in the 10 to $100 \AA$ [14].

\subsection{FT-IR Spectroscopy}

Figure 6 shows the FT-IR transmission spectra of principal bands of the investigated Perylen-PC composite film. The characteristic IR band of C-H from the aromatic rings
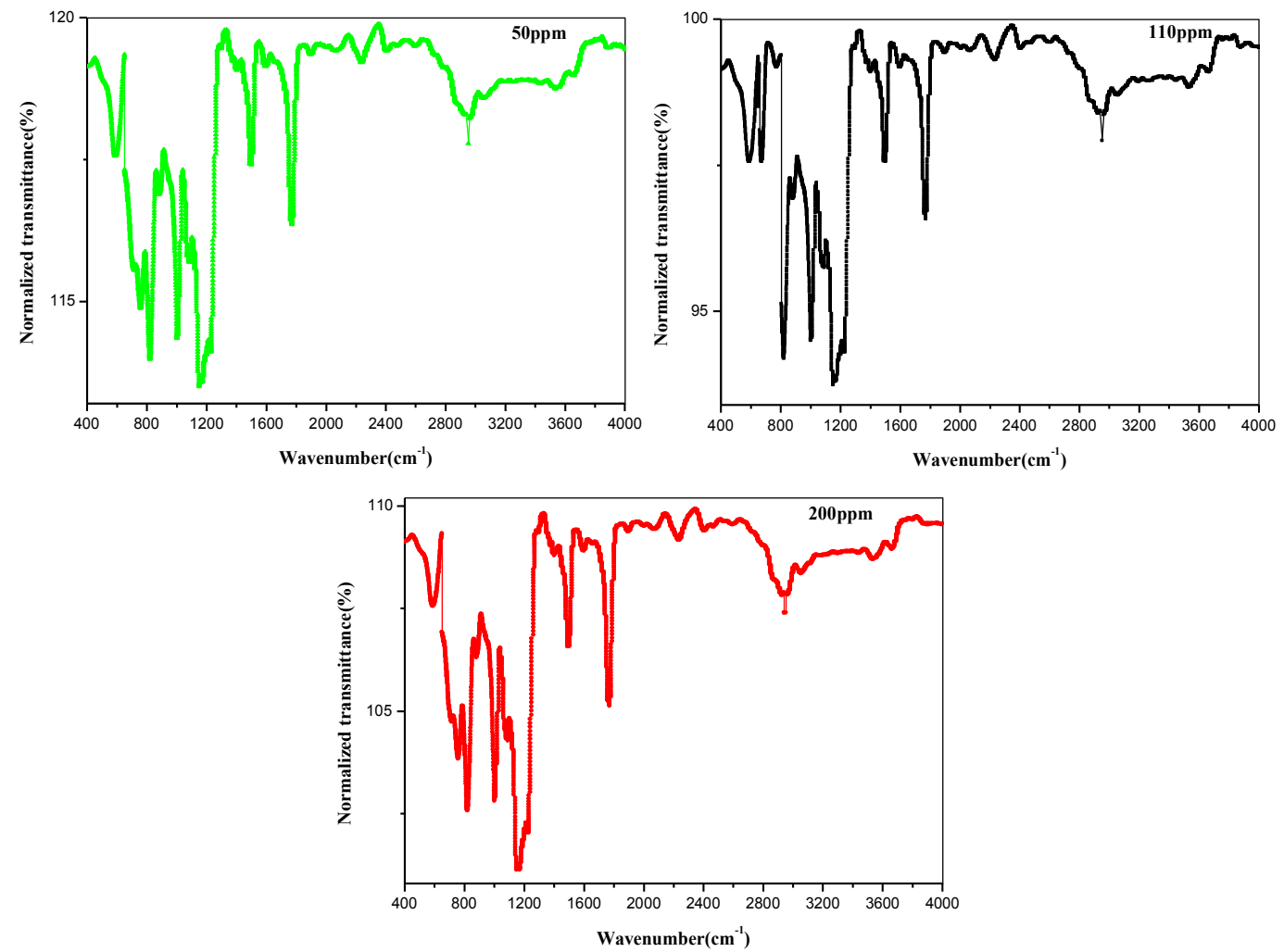

Fig. (6): FT-IR spectrum of Perylene-PC composites at different concentrations a- $50 \mathrm{ppm}$ b- 110 ppm c- 200 ppm.

are observed in the $2972 \mathrm{~cm}^{-1}$. Band around $1781 \mathrm{~cm}^{-1}$ which related to $\mathrm{C}-\mathrm{O}$ stretching vibration of the (Keton) group. Band around $1500 \mathrm{~cm}^{-1}$ which related to $\mathrm{C}-\mathrm{C}$ stretching vibration of the (Aromatic) groups. The stretching of the (Ether) groups O-C-O occurs from 1004 to $1189 \mathrm{~cm}^{-1}$. Band around $554 \mathrm{~cm}^{-1}$ which related to $\left(\mathrm{CH}_{2}\right)_{\mathrm{n}}$ stretching vibration of the (Alkane) group [15].

Comparing the spectral bands of Perylen-PC composite at different concentrations of perylene (50,110 and $200 \mathrm{ppm})$, the absorption detected peaks for all concentrations did not change as in Table (2). From the FT-IR spectra of perylene-PC composites, there is no effect of dye concentration on the chemical bonds inside the polymer. 
Table (2): FT-IR absorption bands of Perylene-PC composites at different concentrations.

\begin{tabular}{|c|l|c|c|c|}
\hline${\text { Wavenumber }(\mathrm{cm})^{-1}}^{-}$ & Assignment & $50 \mathrm{ppm}$ & $110 \mathrm{ppm}$ & $200 \mathrm{ppm}$ \\
\hline 2972 & $(\mathrm{C}-\mathrm{H})$ stretching, Aromatic & 2970.09 & 2974.11 & 2973.31 \\
\hline 1780 & $(\mathrm{C}=\mathrm{O})$ stretching, Ketone & 1784.04 & 1781.23 & 1780.89 \\
\hline 1501 & $(\mathrm{C}=\mathrm{C})$ stretching, Aromatic & 1504.85 & 1501.21 & 1504.67 \\
\hline 1189 & $(\mathrm{C}-\mathrm{O})$ stretching, Ether & 1185.95 & 1189 & 1194 \\
\hline 1004 & $(\mathrm{C}-\mathrm{O})$ stretching, Ether & 1002.41 & 1004.25 & 1001.10 \\
\hline 554 & $\left(\mathrm{CH}_{2}\right)_{\mathrm{n}}$, Alkane & 554 & 554.31 & 554 \\
\hline
\end{tabular}

\subsection{Thermo gravimetric Analysis (TGA)}

The thermal stability for Perylene-PC composites at different concentrations has been studied by using TGA technique as shown in Fig. 7. One can see a little weight loss below $250^{\circ} \mathrm{C}$ was detected which attributed to volatile products removal, of polycarbonates degradation were found to be carbon dioxide and bisphenol-A, with smaller amounts of carbon monoxide, methane, phenol, biphenyl carbonate. Initial degradation starts at the end group which reacts with any free hydrogen present, such as water or free hydroxyl groups. It is reported that, the carbonate group is the principal reason of degradation at temperatures below $400{ }^{\circ} \mathrm{C}$, while at higher temperatures; the isopropylidene group is trend to loss a methyl radical. Below $500^{\circ} \mathrm{C}$, no free radical reactions were observed for the carbonate groups, but rearrangement of the carbonate moietydominates [16].

The thermal decomposition and subsequent weight loss of the solid can be expressed by the following reaction rate equation (coats equation) [17],

$$
\frac{d \alpha}{d t}=\boldsymbol{k}(1-\alpha)^{n}
$$

where $\alpha=\frac{w_{i}-w_{t}}{w_{i}-w_{f}}$ is the loss fraction, $w_{i}$, w fare the initial weight and final weight respectively, $w_{t}$ is the weight at given temperature, $n$ is the reaction order takes the values 1 to 4 and $k$ is the reaction rate constant, which represented by Arrhenius equation,

$$
k=A e^{-E / R T}
$$

where $R$ is the universal gas constant, $E$ is the decomposition energy, $T$ is the absolute temperature and $A$ is the frequency factor. The degradation kinetics $(\mathrm{n}=1)$ of the presented PC with different concentrations of perylene can be expressed by the following relation,

$$
\log \left[\frac{-\log (1-\alpha)}{T^{2}}\right]=\log \left[\frac{\left(1-\frac{2 R T}{E}\right) A R}{\beta E}\right]-\frac{E}{2.303 R T}
$$


The values of $E$ have been extracted using the least square fitting of Eq. (7), and listed in Table 3 where $\beta$ is the heating rate. It's clear that, perylene did not affect the thermal stability of PC. The present results of polymer composites confirmed from the FT-IR study.

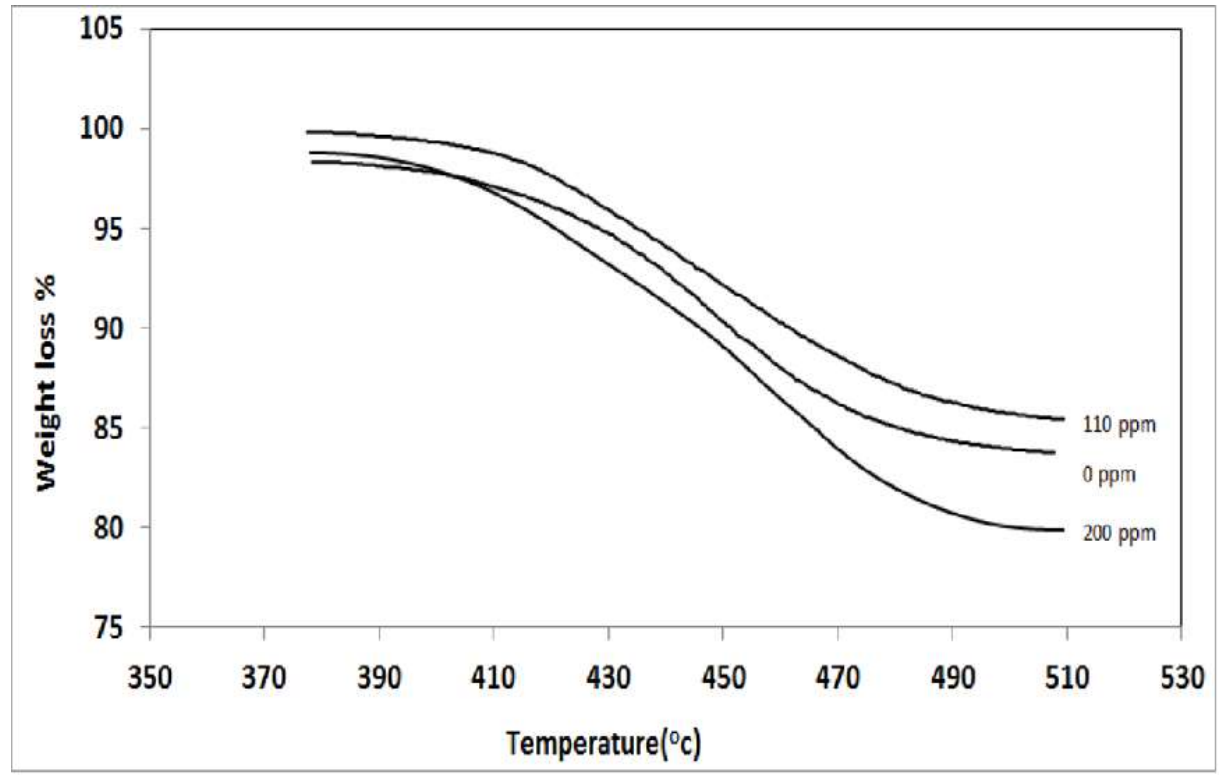

Fig. (7): Weight loss of Perylene-PC composites at different concentrations vs. Temperature

\subsection{Differential scanning calorimetric (DSC)}

Figure (8) shows the DSC thermo-grams for Perylene-PC composites at different concentrations of Perylene dye. Two endothermic peaks appear, the first around $82^{\circ} \mathrm{C}$ and the second around $287^{\circ} \mathrm{C}$ refer to the glass transition temperature, $\mathrm{T}_{\mathrm{g}}$ and melting temperature, $\mathrm{T}_{\mathrm{m}}$ respectively for selected concentrations of Perylene upto 200 ppm, as listed in Table (3).

It is clear that, no change of the position of both glass transition temperature and this confirms that no interaction of between dye and polycarbonate. 


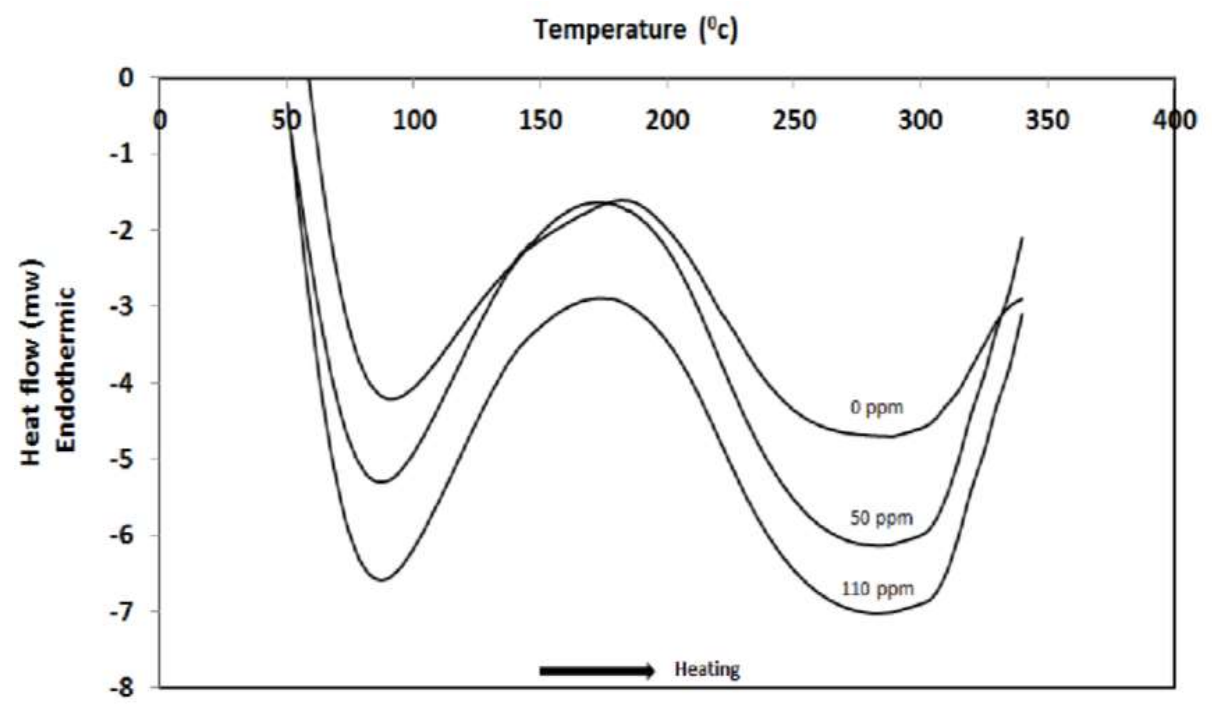

Fig. (8): DSC results of Perylene-PC composite at different concentrations

Table (3): Thermal parameters of perylene-PC composites at different concentrations.

\begin{tabular}{|c|c|c|c|}
\hline $\begin{array}{c}\text { Concentration } \\
(\mathrm{ppm})\end{array}$ & $\begin{array}{c}\text { Methylene chloride } \\
\text { release temperature }\left({ }^{0} \mathrm{c}\right)\end{array}$ & $\begin{array}{c}\text { Melting } \\
\text { temperature }\left({ }^{0} \mathrm{c}\right)\end{array}$ & $\begin{array}{c}\text { Decomposition } \\
\text { energy }(\mathrm{kj} / \mathrm{mole})\end{array}$ \\
\hline 0 & 80.3 & 288 & 165.351 \\
\hline 50 & 83.55 & 287.58 & 165.54 \\
\hline 110 & 82.775 & 287.86 & 165.6 \\
\hline 200 & 82.446 & 288.24 & 166.45 \\
\hline
\end{tabular}

\subsection{Complex impedance spectroscopy}

\subsubsection{Bulk conductivity}

The complex impedance analysis method was used to determine the bulk electrical conductivity $\sigma_{b}$ of all samples. The impedance was analyzed to a real part $Z$ and imaginary part $Z^{\prime}$ on the complex plane at room temperature for perylene-PC composites as shown in Fig. 9. The impedance plot, in general, shows a semicircle its center is below the $Z^{\prime}$ axis where the semicircle reflects the impedance of charge transfer. The intersection with $Z^{\prime}$ axis represents the sample bulk resistance $R_{b}$ at high frequency region. The values of bulk conductivity $\sigma_{b}$ of the polymer composites were obtained by Eq. (8) [18].

$$
\sigma_{b}=d / R_{b} A
$$

where $d$ is the sample thickness and $A$ is its effective area for different concentrations of polymer composite.

As listed in Table (4), the values of bulk resistance and bulk conductivity are concentration dependent. 


\subsubsection{Dielectric Parameters}

In the present section the dielectric parameters $\varepsilon^{\prime}$ and $\varepsilon^{\prime \prime}$ are studied in wide range of frequencies at room temperature. Fig. 10 shows the variation of the dielectric constant $\varepsilon^{\prime}$ and dielectric loss $\varepsilon^{\prime \prime}$ versus frequency for all concentrations of Perylene in PC matrix. It can be noticed that and $\varepsilon^{\prime}$ and $\varepsilon^{\prime \prime}$ decreased with increasing frequency in the frequency range of $\omega \tau \gg>1$ for Perylene-PC composites. This behavior can be described by the Debye dispersion relations [Eq. (9) and Eq. (10)] [19].

$$
\begin{array}{r}
=_{\infty}+\frac{s^{-}}{1+22} \\
\cdots=\frac{\left(s^{-}\right)}{1+22}
\end{array}
$$

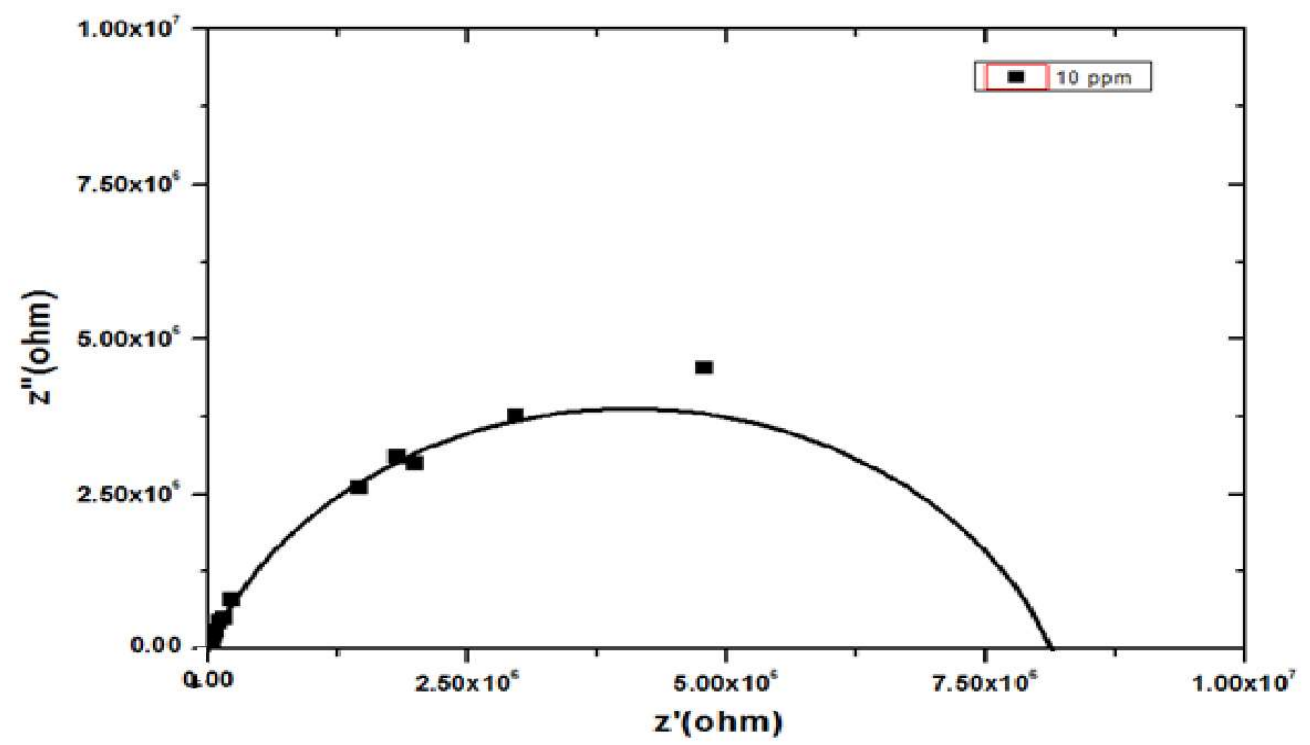

Fig. (9): The impedance plot of the imaginary part $Z^{\prime}$ " against the real part $Z$ ' at room temperature for concentration of $10 \mathrm{ppm}$.

Table (4): Bulk resistance and bulk conductivity of perylene-PC composites at different concentrations.

\begin{tabular}{|c|c|c|}
\hline Concentration $(\mathrm{ppm})$ & Bulk resistance $(\mathrm{ohm})$ & Bulk conductivity $\left(\mathrm{ohm}^{-1} \mathrm{~m}^{-1}\right)$ \\
\hline 0 & $8.19 \mathrm{E}+06$ & $4.09046 \mathrm{E}-07$ \\
\hline 10 & $8.18 \mathrm{E}+06$ & $4.09546 \mathrm{E}-07$ \\
\hline 200 & $8.18 \mathrm{E}+06$ & $4.35142 \mathrm{E}-07$ \\
\hline 30 & $8.20 \mathrm{E}+06$ & $3.57478 \mathrm{E}-07$ \\
\hline 50 & $8.23 \mathrm{E}+06$ & $3.81616 \mathrm{E}-07$ \\
\hline 70 & $8.24 \mathrm{E}+06$ & $4.06564 \mathrm{E}-07$ \\
\hline 90 & $8.25 \mathrm{E}+06$ & $3.55312 \mathrm{E}-07$ \\
\hline 110 & $8.14 \mathrm{E}+06$ & $3.85836 \mathrm{E}-07$ \\
\hline 150 & $8.16 \mathrm{E}+06$ & $4.10549 \mathrm{E}-07$ \\
\hline
\end{tabular}



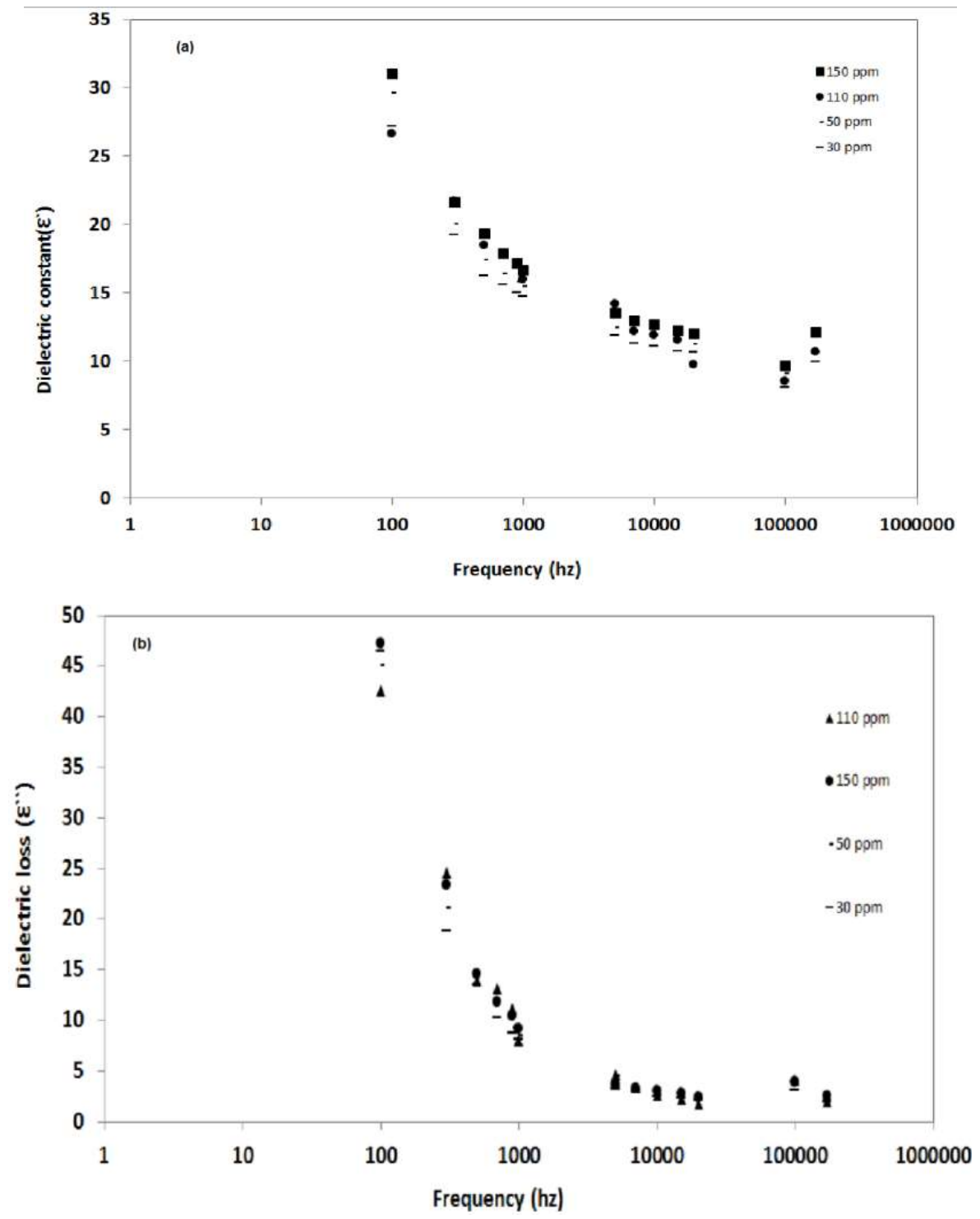

Fig. (10): The variation of a- dielectric constant $\varepsilon^{\prime}$ and b- dielectric loss $\varepsilon^{\prime \prime}$ versus frequency at different concentrations of perylene.

where $\varepsilon_{0}$ is the dielectric constant at low frequency, $\varepsilon_{\infty}$ is the dielectric constant at high frequency, $\omega$ is the angular frequency, and $\tau$ is the relaxation time.

The decrease of $\varepsilon^{\prime}$ and $\varepsilon^{\prime \prime}$ with frequency can be associated to the inability of dipoles to rotate rapidly leading to a lag between frequency of oscillating dipole and that of applied field. The variation indicates that, at low frequencies; the dielectric constant is high due to the interfacial polarization and the dielectric loss $\left(\varepsilon^{\prime \prime}\right)$ becomes very large due to ionic or molecular polarizations [20]. In addition no remarkable variation of dielectric constant or dielectric loss with perlynene concentration which confirms that there are no changes in the polymer matrix polarization 


\section{Conclusion}

From the obtained results and discussion one concludes the following: The optical absorption as well as the florescence peaks clearly illustrated at 574 and $612 \mathrm{~nm}$ respectively. The UV-VIS, TGA, DSC and FT-IR did not illustrate variation of the optical energy gap, $2.08 \mathrm{eV}$, decomposition energy $165.5 \mathrm{k}$ $\mathrm{J} /$ mole, melting temperature $288^{\circ} \mathrm{C}$ and FT-IR absorption bands at different concentrations of perylene. This clearly confirms that, there is no chemical interaction between perylene and PC as well as degree crystallinity of the matrix. The study of the dielectric strength and the electrical resistance values illustrated that Perylene-PC composites are efficient matrix for transmission and florescence.

\section{References}

1. W. D. Callister, Materials Science and Engineering, John Wiley \& Sons, new York, (2007).

2. C. Espejo1, A. Arribas, F. Monzo', P. P. Di'ez, Nanocomposite films with enhanced radiometric properties for greenhouse covering applications, J. of Plastic Film \& Sheeting, 28(4) (2012) 336-350.

3. M. k. Mishra, Y.Yagci, Handbook of Vinyl Polymers radical polymerization, process, and technology, Taylor\& Francis Group, LLC, NEW YORK, 2009.

4. A. Ait-Kadi, M. Bousmina, A.A. Yousefi, F. Mighri,High Performance Structured Polymer Barrier Films Obtained From Compatibilized Polypropylene/EthyleneVinyl Alcohol Blends, Poly. Eng. \& Sci., 47 (2007) 1114-1121.

5. H. Becker, L. E. Locascio, review Polymer microfluidic devices, Talanta, 56 (2002) 267-287.

6. Dr. A. Seidel,Encyclopedia of Polymer Science and Technology,John Wiley \& Sons, Inc,111 River St., 8-01 , Hoboken, NJ 07030-5774, (2014).

7. M. G. El-Shaarawy, A. F. Mansour, S. M. El-Bashir, M. K. El-Mansy, M. Hammam,Electrical Conduction and Dielectric Properties of Poly(methyl methacrylate)/Perylene Solar Concentrators, J. of App. Poly. Sci., 88 (2003)793-805.

8. B.C. Rowan, L. R. Wilson, B. S. Richards, Advanced Material Concepts for Luminescent Solar Concentrators, IEEE J. of Selected Topics In Quantum Electronics, 14 (2008)1312-1322.

9. L. Bai, Optical properties of $\mathrm{CdGeAs}_{2}$, Morgantown, West Virginia, (2004).

10. R. M. Ahmed, S.M. El-Bashir,Structure and Physical Properties of Polymer Composite Films Doped with Fullerene Nanoparticles, Hindawi Publishing Corporation, (2011) 2010.

11. S. M. El-Bashir, O. A. AlHarbia, M.S. AlSalhia, Optimal design for extending the lifetime of thin film luminescentsolar concentrators, Optik,125 (2014) 5268-5272. 
12. A.F Mansour,M.G. El-Shaarawy, S.M. El-Bashir, M.K. El-Mansy, M. Hammam, Optical study of perylene dye doped poly(methylmethacrylate) as fluorescent solar collector, Polymer Int., 51 (2002) 393-397.

13. B. Valeur, Molecular Fluorescence: Principles and Applications, Wile y-VCH Verlag GmbH, NEW YORK, 2001.

14. V. V. Didenko, Fluorescent Energy Transfer Nucleic Acid Probes: Designs and Protocols, Humana Press Inc., New Jersey, (2006).

15. E. Ghorbel, I. Hadriche, G. Casalino, N. Masmoudi,Characterization of Thermo-Mechanical and Fracture Behaviors of Thermoplastic Polymers, Materials,7 (2014) 375-398.

16. A. Davis, J. H. Golden, Thermal Degradation of Polycarbonate, J. Chem.Soc, B, (1968) 45-47.

17. S. Maitra, S. Mukherjee, N. Saha, J. Pramanik,Non-isothermal decomposition kinetics of magnesite, Cerâmica,53 (2007) 284-287.

18. S. A. Mohamed, A.A. Al-Ghamdi, G.D. Sharma, M.K. El Mansy,Effect of ethylene carbonate as a plasticizer on CuI/PVA nanocomposite: Structure, optical and electrical properties, J. of Adv. Research, 5 (2014) 79-86.

19. V. S. Member, IAENG, D.K. Sahu, Y. S. Member, IAENG, D.C.Dhubkarya, the Effect of Frequency and Temperature onDielectric Properties of Pure Poly VinylideneFluoride (PVDF) Thin Films, IMECS, 3 (2010).

20. H. M. El Ghanem1, S.A. Saqa'n, M. Al Saadi, S. M. Abdul Jawad, On the Electrical and Optical Properties of Polycarbonate/MNCl2 Composite, J. of Modern Physics, 2 (2011) 1553-1559. 